University of Montana

ScholarWorks at University of Montana

6-1983

\title{
A Test of Concepts Inherent in Experience Based Setting Management for Outdoor Recreation Areas
}

\author{
Michael J. Manfredo \\ Oregon State University \\ B. L. Driver \\ USDA Forest Service, Rocky Mountain Forest and Range Experiment Station \\ Perry J. Brown \\ University of Montana - Missoula, perry.brown@umontana.edu
}

Follow this and additional works at: https://scholarworks.umt.edu/forest_pubs

Part of the Forest Management Commons

Let us know how access to this document benefits you.

\begin{abstract}
Recommended Citation
Manfredo, Michael J.; Driver, B. L.; and Brown, Perry J., "A Test of Concepts Inherent in Experience Based Setting Management for Outdoor Recreation Areas" (1983). Forest Management Faculty Publications. 36. https://scholarworks.umt.edu/forest_pubs/36
\end{abstract}

This Article is brought to you for free and open access by the Forest Management at ScholarWorks at University of Montana. It has been accepted for inclusion in Forest Management Faculty Publications by an authorized administrator of ScholarWorks at University of Montana. For more information, please contact scholarworks@mso.umt.edu. 


\title{
A Test of Concepts Inherent in Experience Based Setting Management for Outdoor Recreation Areas
}

\author{
Michael J. Manfredo, B. L. Driver, \\ and Perry J. Brown
}

ABSTRACT: This study examines assumptions of the concepts which form the basis for experience based setting management of outdoor recreation areas. To lest the assumptions a sample of wilderness users was surveyed and divided into experience groups based on differences in the specific experiences they desire. These experience groups were then lested for differences in their activity and setling preferences. The study was conducted at the Bridger Wilderness, the Fitzopatrick Wilderness, and the Popo Agie Primitive Area in Wyoming during 1978-79. Data were collected by questionnaire, and responses were examined by object cluster analysis to group users on the basis of the types of experiences important to them. Results offer support for the concepts lested; three groups with different preferences for experiences were idenlified and were found to differ on the activities, setting, and management actions they prefer. Directions for future research are given and recommendations concerning the usefulness of experience based information to recreation planning are discussed.

KEYWORDS: Experience-based recreation setting management, recreation management, experience preferences, management preferences, wilderness recreation.

AUTHORS: Michael J. Manfredo is Assistant Professor and Perry J. Brown is Professor and Head of the Department of Resource Recreation Management, Oregon State University, Corvallis. B. L. Driver is Research Forester, USDA Forest Service, Rocky Mountain Forest and Range Experiment Station, Fort Collins.

Journal of Leisure Research, 1983 Volume 15, Number 3, pp. 263-283. Copyright ${ }^{\circ} 1983$ by the National Recrealion and Park Association.

\section{Purpose}

A frequently cited goal of recreation management-to provide opportunities for a wide range of satisfying recreation experiences appropriate for a given area - has been emphasized with slight variation by many researchers. Wagar $(1964 ; 1974)$ suggested managing recreation areas to meet a range of 
human needs; Driver and Tocher (1970) to provide opportunities for the "package" of highly desired experiences; Brown, Dyer, and Whaley (1973) to satisfy recreationist motives; Lucas and Stankey (1974) to maximize user satisfactions; and Hendee (1974) to provide multiple satisfactions. In a similar fashion Driver and Brown $(1975 ; 1978)$ have called for planning that delineates the opportunities for experiences offered to users. In addition, they have offered a model of the recreation decision process useful in guiding behavioral research which will aid managers in meeting their goals (Driver and Brown 1975; 1978; Haas, Driver and Brown 1981).

The model proposed by Driver and Brown gives a general framework for understanding why recreationists are motivated to engage in specific recreation activities at specific areas. Their model was influenced heavily by developments in psychology's expectancy valence theory. Though this influence has been noted in several articles (Driver 1976; Driver and Brown 1975), it is best explicated in work by Haas, Driver and Brown (1981) using Lawler's expectancy valence formulation. Lawler proposes that one's motivation to engage in a behavior is a function of primarily two types of expectancies. One is the expectation that one's efforts will lead to certain performances, and the second is the expectation that these performances will lead to positively valued outcomes (Lawler 1973). Within this framework it is proposed that the motivation to engage in a given recreation opportunity is a function of (1) the expectation that one's efforts to recreate (e.g., expend money, travel, plan) will lead to performance (participation in certain activities at a specific type of setting), and (2) the expectation that the performance will lead to desired experience. In this model, recreation activities are behaviors such as hunting, hiking, and fishing. Settings are the places where activities take place and include all physical resource (e.g., topography, water, wildlife, fish, meadow) social (e.g., number of others, type of others) and managerial (e.g., fee systems, permits, facilities) conditions of these places. Experiences are defined as a package of specific psychological outcomes which are realized from a recreation engagement.

Two major conclusions can be drawn from this model. First, we define recreation opportunities as options to engage in a specific activity at a specific setting to realize desired experiences. This definition identifies three facets of recreation demand and supply: demands for an activity opportunity, a setting opportunity, and an experience opportunity (Driver and Brown 1975; 1978).

Second, the earlier stated goals of recreation management (e.g., providing desired opportunities for experiences) best can be met by understanding the relationship between the valued psychological outcomes of a recreation activity and the types of settings which facilitate those outcomes. With this type of information managers can increase the probability that users will realize desired experiences and activities by ensuring that the physical, social and managerial settings which help facilitate them are available. This approach has been referred to as experience-based recreation setting management (Driver and Rosenthal 1982).

Although the logic and empirical support for experience-based setting management is still emerging, the approach has been gaining acceptance in recreation resource management training and practice. For example, the rea- 
soning behind that approach and limited empirical data on relationships between user preferences for activity, setting and experience opportunities were part of the conceptual base for development of the Recreation Opportunity Spectrum, a planning system currently in use by land management agencies such as the U. S. Forest Service and Bureau of Land Management (Brown, Driver and McConnell 1978; Buist and Hoots 1982; Clark and Stankey 1979; Driver and Brown 1978.)

As a theoretical construct for guiding research and management, these concepts need further examination. The purpose of this research was to provide an initial test of these concepts by examining the relationship between activities, experiences, and settings desired by wilderness recreationists using the Wind River Range in Wyoming.

\section{Hypotheses}

Past research tends to support the notion that those participating in different recreational activities receive different patterns of experience outcomes. For instance, Driver (1976) presented results showing there is some variability in the psychological outcomes important in activities such as camping, biking and tennis. Similarly, Brown (1981) in comparing results of studies of hikers, backpackers, fishermen, hunters, ORV users, river runners, and cross country skiers indicated some similarities and differences in experience outcomes which are important for participants in these activities.

Though research has shown a relationship between activities and experience outcomes desired by recreationists, it has also shown that activity classifications alone are inadequate for defining homogeneous experience groups (i.e., those having relatively common experience outcomes). Several studies have been conducted which have found that recreationists grouped by traditional activity classifications can be further segmented according to the psychologically defined experiences they prefer. Using a survey instrument designed to measure "desired psychological outcomes" and object cluster analysis, Brown and Haas (1980) found five separate experiences desired by the wilderness recreationists they surveyed. These user types were distinguishable by the emphasis placed on outcomes such as Escaping Pressure, Autonomy, and Achievement.

In studies using a similar methodology Driver and Cooksey (1980), and Manfredo, Brown and Haas (1980) found distinct experience groups among fishermen;' Ballman, Knopp and Merriam (1981), Haas, Driver and Brown (1981) and McLaughlin and Paradice (1980), found different experience groups among cross-country skiers; and Hautaluoma and Brown (1978) found similar groupings among hunters.

Several studies have found relationships between settings and experience preferences. For example, Brown et al. (1977) found a relationship between management preferences and experiences among hunters. Ballman et al. (1981) and McLaughlin and Paradice (1980) offer some support for a relationship between social, resource, and managerial attributes of a setting and desired cross-country skiing experiences. Also, research by Brown and Ross 
(1982) testing notions inherent in the Recreation Opportunity Spectrum, suggests that desires for specific experiences are related to preferences for different recreational settings. Despite these findings more research is needed on the relationship between desired experiences and the settings which facilitate them to confidently apply this concept in management (Brown 1981; Brown and Haas 1980; Harris 1981).

Examination of these past studies and the conceptual framework offered by Driver and Brown $(1975 ; 1978)$ led to the following hypotheses:

1. There are definable segments of wilderness recreationists which differ according to the experience they desire. Desired experience is defined here as it has been in several past studies: it is the package of specific psychological outcomes desired by a recreationist when choosing to engage in a specific recreation activity.

2. Physical, social and managerial setting preferences differ among wilderness recreationists desiring different types of experiences.

3. Activity participation differs among wilderness recreationists desiring different experiences.

\section{Procedures}

The study population included recreationists who used the Popo Agie Primitive area and the Fitzpatrick and Bridger Wilderness areas during the summer of 1978. These areas are located in Wyoming's Wind River range southeast of Teton National Park. The Bridger ( $970 \mathrm{sq} \mathrm{km}$ ) stretches approximately 130 kilometers along the west side of the Continental Divide. The Fitzpatrick (430 sq km) and the Popo Agie $(170 \mathrm{sq} \mathrm{km})$ are contiguous with the Bridger and are located on the east side of the Divide. The areas are popular for private recreation excursions but are also used by organized groups and outfitters. Forest Service estimates of recreation use in 1977 were 50,000, 23,000 and 220,000 visitor days for the Popo Agie, Fitzpatrick and Bridger, respectively. Estimates prior to 1977 indicate annual use had been steadily increasing.

Survey research techniques were employed to collect data with the sample frame for mail questionnaires developed on-site. Subjects questioned were non-commercial recreation users of the areas; outfitters, commercial groups, and organized groups were not included in the study. Names and addresses were obtained from interviews at trailheads and mailback postcards distributed on windshields of cars parked at trailheads. In both approaches the users were told the purpose of the study and that later they would be sent a mail questionnaire. They were then asked to participate.

Samples were obtained at all primary trailheads for the.Popo Agie and Fitzpatrick areas and two of the ten primary trailheads for the Bridger area. The Bridger Trailheads sampled were those most used for western access to the Popo Agie and Fitzpatrick areas.

The strategy for sampling involved stratifying by trailhead and time of week. Within these strata, time periods containing clusters of users were ran- 
domly sampled. All recreationists within a cluster were sampled. Since travel distances limited the number of times that Bridger trailheads could be sampled, a mailback postcard was used to supplement the sample of Bridger recreationists. At the end of each sampling day, mailback postcards were placed on the windshields of cars parked at these trailheads. Four hundred fortysix of these cards were distributed, of which 37 percent were returned. Comparisons of these subjects' responses to the reponses of interviewed subjects revealed no differences between the two groups, so the two groups of subjects using the Bridger Wilderness were pooled.

All subjects were sent a follow-up questionnaire. This questionnaire was designed to collect information concerning preferences for psychological outcomes, setting attributes and potential management actions. Additional information was collected concerning respondents' activities during the trip.

To assess experience outcomes, forty-six items were selected from a pool of items.' Psychological outcome items were sampled to represent a broad range of outcomes potentially important to people. Seventy-two items measuring setting attribute preferences and 57 items measuring preferences for management actions were also included on the questionnaire. These items were developed using judgment, results of past research, input from area managers, and data from Shoshone National Forest public involvement efforts. For each set of items, subjects were asked to indicate whether the item listed would add to or detract from their satisfaction on a trip similar to the one they had when they were contacted. We did not ask for specific reports of past trips in order that we might pose hypothetical management actions, setting attributes, and psychological outcomes to which users could react.

Responses to outcome, setting, and management action items were elicited on a 9-point response format with the following response categories: Most Strongly Adds (+4), Strongly Adds (+3), Moderately Adds (+2), Slightly Adds $(+1)$, Neither Adds nor Detracts (0), Slightly Detracts $(-1)$, Moderately Detracts $(-2)$, Strongly Detracts $(-3)$, Most Strongly Detracts(-4).

The questionnaire was pretested for clarity by administering it to recreationists during a two week period at the beginning of the 1978 use season. Of 96 pretest questionnaires, 36 were returned. Evaluation of these responses indicated. few changes were needed. Pretest respondents were included in the group of study respondents and pretest non-respondents were sent a questionnaire when the mailing was made to all other subjects in the study. Thus the pretest subjects were pooled with other subjects in the study.

Data were analyzed in three stages. First, three separate I-Clust variable cluster analyses (Revelle 1977) were performed on each set of items relating to experience outcomes, setting attributes and potential management actions. These analyses provided clusters of empirically associated groups of items for each set included on the questionnaire.

'Items were selected from a pool developed to measure 42 different outcomes in 20 domains. They are available from B. L. Driver, Rocky Mountain Forest and Range Experiment Station, Fort Collins, Colorado. 
I-Clust is a hierarchical routine which uses the unattenuated correlation as a measure of similarity. Two statistics are used for identification of a cluster: (1) alpha, which is Cronbach's (1951) estimate of internal consistency and is the mean of all possible split half reliabilities, and (2) beta, which is the worst possible split half reliability of a test. A cluster of items is identified when the joining of items to a cluster no longer increases either the alpha or beta. Means for a cluster were computed by summing and averaging each respondent's cluster mean. A subject was treated as having missing data for a cluster only if he had no valid scores for items in a cluster.

In a second stage of analysis, groups of subjects rating the experience outcome clusters similarly were identified by NORMIX object cluster analysis (Wolfe 1978; 1970). These groups are subsequently called experience groups. NORMIX seeks maximum likelihood estimates of the parameters of a mixture of multivariate normal distributions. The likelihood equations are solved iteratively through the estimation of the probability of an object's membership in each cluster until the likelihood reaches a relative maximum. Each object in the sample is assigned a probability of membership in each cluster. After groupings are assigned, data are tested for the number of significantly different groups in the sample using a ratio of maximum likelihood estimates for two different hypotheses concerning the number of groups in the sample. This ratio provides a significance test for rejecting the null hypothesis of the smaller number of types against the alternative of the larger number (Wolfe 1970). Further tests were conducted using one-way analysis of variance and StudentNeuman-Keuls test for mean differences to identify the specific outcome clusters on which groups differed.

In the third stage of analysis, the experience groups were examined for differences in their rating of setting attributes, potential management actions, and activities. Chi-square was used to test for differences among activities, while analysis of variance and the Student-Newman-Keuls test were used to test for differences among other variables.

\section{Results}

Of the 434 questionnaires distributed, 307 were returned. Ten were marked return to sender leaving a response rate of 74 percent. Response rates of 79 percent $(N=135), 75$ percent $(N=77)$, and 59 percent $(N=95)$ were obtained from the Bridger, Fitzpatrick and Popo Agie users, respectively.

Given the close geographic proximity of the study areas and the similarities of their environments, respondents were pooled for analysis. Tests for differences between the areas on the experience group variable were not significant $(p \leqslant .05)$.

\section{Outcome Setting and Management Clusters}

The variable cluster analyses produced 13 psychological outcome, 16 setting attribute, and 14 management action preference clusters. The assignment 
of items to clusters, titles assigned to each cluster and alpha statistics are shown in Table 4. All clusters but one, Resource Restoration, had alpha values greater than 0.50, which is Revelle's (1977) suggested criterion for indication that a cluster is internally consistent. The decision was made, however, to retain this cluster, because its alpha (.48) was quite close to the .50 criterion. Overall means on the psychological outcome clusters are shown in the second column of Table 1 while means on the setting and management scales are in the second column of Table 2. The remainder of both tables show experience group means which are discussed in the next two sections.

The first column of numbers in Table 1 shows the overall relative importance of the 13 wilderness-related psychological outcomes to the users of the three study areas. Those scores show that, on the average, all the experiences, with the possible exception of meeting and observing new people ( $\bar{x}$ of 0.2$)$, would add to the satisfaction that would be expected from a future similar trip to the area. In fact, the first four clusters, which indicate satisfaction related to nature enjoyment, solitude-tranquility, exercise and learning added strongly to most strongly ( $\overline{\mathrm{x}}$ scores of 3.0 to 3.5 ). The next four including escaping pressure, gaining autonomy, being with similar people, and achievement-self realization added moderately to strongly ( $\bar{x}$ scores 2.7 to 2.8 ). Therefore, these eight outcomes were, on the average, quite important to the users and include those which are commonly associated with the concept of wilderness recreation. The remaining five were positive, but less so, and their sizable standard deviations indicate a wider range of importance to users. Given the study sample, wilderness recreationists, it is not surprising that meeting and observing new people had the lowest means and standard deviations.

The second column of numbers in Table 2 shows means on the setting attribute and management action preference clusters. The highest scored setting attribute was resource characteristics such as wildlife, streams, and wide views ( $\bar{x}$ of 3.1 ) which added strongly to satisfaction. Additionally, rugged terrain, fish, and water without access, were rated as adding moderately to strongly to satisfaction ( $\bar{x}$ range from 2.4 to 2.9 ). Information and easy travel were also positive but only slightly so ( $\bar{x}$ of 1.9 and 1.6$)$.

The remaining setting attributes, crowding (seeing others, contacting others, presence of outfitters), impact of others (on structures, trails, soil, vegetation; violation of wildland ethics), domestic animals and pets, and absence of regulations, were perceived to detract slightly to strongly from a user's experience.

Of the 14 clusters pertaining to potential management action, users perceived 11 to be positive (Table 2). As might be expected, the most positive response was elicited by iterns with the least coercive impact on noncommercial users and concerned mitigation of problems relating to domestic animals, ability to obtain information, restrictions on outfitter and commercial groups, and limitations on party sizes. Of the three management actions eliciting negative responses, two pertained to restrictions on travel in the wilderness and one to development in the area. Overall the standard deviations were much higher for this set of items than for the experience or setting attribute items. 


\section{User Groups}

User groups were identified using object cluster analysis. Since there was no expectation that experience groups should differ on every desired experience outcome, and because of limitations within NORMIX, only 5 of the 13 outcome clusters were used in forming groups. These were security, autonomy, achievement, leadership, and risk taking. In the absence of pre-existing information as to exactly which clusters to use, judgments were made in selecting these clusters. These decisions were guided by managers' perceptions of the types of recreationists at the study areas and inferences concerning the experience outcomes which may be differentially important to recreationists. As a check against this choice of clusters, additional analyses were conducted using other combinations of clusters. The initial analysis produced results giving the most distinct user groups and is reported here.

Of the 307 questionnaires, 48 had missing data and could not be used in object cluster analysis, and 14 were unique and not classified. A chi-square test (Wolfe 1970) of the hypothesis that there were three instead of two groups was significant $\left(p<0.05, x^{2}=88.2,40\right.$ d.f. $)$. The test for four instead of three groups was not significant ( $p<0.05, x^{2}=37.65,40$ d.f.). Of those classified, 21 percent were in Group I, 19 percent in Group II, and 60 percent in Group III.

To identify specific statistically significant differences between group means, an analysis of variance and a Student-Newman-Keuls test were conducted on each experience outcome cluster. Table 1 shows results of this analysis as well as the mean for each group across all outcome clusters. Analysis of variance revealed that group means differed on all clusters except one, family togetherness, However, Group III had means not significantly different from Group I on being with similar people, security and meeting other people and means not significantly different from Group II for exercise, learning and escape pressure. Additionally, Group II had a mean not significantly different from Group I on nature.

The most notable distinctions of Group I are (1) its 2-point separation from Group III and more than 3-point separation from Group II on risk taking and (2) its .5 to 1.5 scale point separation from Groups II and III on autonomy, achievement, escape pressure, and leadership. It is not surprising that those are the clusters on which the greatest separation was found since all but one were used in the object analyses.

Though Group II differed from others on most of the clusters, it is most distinguishable in having the lowest means on risk-taking, security (being near helpful people), and meeting new people. This group had the lowest (and only negative) mean in its rating of meeting and observing new people, which was two points lower than the ratings by Groups I and III. Additionally, the Group II mean for risk taking is more than two points lower than those of Groups I and III and the Group II mean for security is more than one point lower than those for Groups I and III.

Group III had no mean as extreme as either Group I or II. It did rate escaping physical pressure, nature and autonomy lowest among all groups. In 
TABLE 1

Overall Means and Standard Deviations for the Psychological Outcome Clusters and Statistically Significant Different Means on Those Scales by the Three Experience Groups. ${ }^{1}$

\begin{tabular}{|c|c|c|c|c|c|c|}
\hline \multirow[b]{2}{*}{ Psychological Outcome Cluster } & \multicolumn{2}{|c|}{$\frac{\text { Eatire Sample }}{(n=307)}$} & \multirow[b]{2}{*}{$\begin{array}{l}\text { Anova } \\
\text { F-Test }\end{array}$} & \multicolumn{3}{|c|}{ Experience Group Means } \\
\hline & Mean & $\begin{array}{l}\text { Standard } \\
\text { Deviation }\end{array}$ & & $I(n-51)$ & $1 I(n-48)$ & III(n-146) \\
\hline Relationships with Nature & 3.5 & 0.6 & $10.5^{*}$ & $3.8 \mathrm{a}^{2}$ & $3.6 \mathrm{a}$ & $3.4 \mathrm{~b}$ \\
\hline Solitude - Tranquility & 3.5 & 0.6 & $17.4^{\circ}$ & $3.8 \mathrm{a}$ & $3.6 \mathrm{~b}$ & $3.3 \mathrm{c}$ \\
\hline Exercise-Physical Fitness & 3.3 & 0.8 & $5.7^{\circ}$ & 3.7a & $3.3 b$ & $3.2 \mathrm{~b}$ \\
\hline Autonomy ${ }^{3}$ & 2.8 & 0.9 & $57.9^{\circ}$ & $3.6 a$ & $3.0 \mathrm{~b}$ & $2.3 c$ \\
\hline Being With Similar People & 2.7 & 1.1 & $7.6^{\circ}$ & $2.7 \mathrm{a}$ & $2.2 b$ & $2.9 \mathrm{a}$ \\
\hline Achievement-Self Realization's & 2.7 & 0.8 & $42.7^{\circ}$ & $3.5 \mathrm{a}$ & $2.5 b$ & $2.5 b$ \\
\hline Family Togetherness & 2.3 & 1.7 & 0.4 & 2.3 & 2.4 & 2.2 \\
\hline Security ${ }^{3}$ & 1.9 & 1.4 & $23.7^{\circ}$ & $2,0 a$ & $0.9 \mathrm{~b}$ & $2.3 \mathrm{a}$ \\
\hline Risk Takings & 1.6 & 1.6 & $117.1^{\bullet}$ & $3.5 \mathrm{a}$ & $0.1 \mathrm{~b}$ & $1.5 c$ \\
\hline Leadership ${ }^{3}$ & 1.6 & 1.7 & $18.3^{*}$ & $2.3 a$ & $1.0 \mathrm{~b}$ & $1.6 \mathrm{c}$ \\
\hline
\end{tabular}

'Cluster scores were computed as the mean of valid scores on items within a cluster. See Table 4 for items composing each cluster. The response formats for items ranged from Most Strongly Adds ( + 4) through Neither Adds nor Detracts $(0)$ to Most Strongly Detracts $(-4)$ to/from Satisfaction.

${ }^{2}$ Means with different subscripts are those which differed significantly $(p<.05)$ using Student-Neuman-Keuls test for mean differences.

These scales were used in the NORMIX object cluster analysis which resulted in determining the three experience preference groups.

- These tests were statistically significant $(\mathrm{p}<.05)$. 
TABLE 2

Overall Means and Standard Deviations ${ }^{1}$ for the Setting Attribute and Management Clusters and Statistically Significant Different Means on Those Scales by the Three Experience Groups.

\begin{tabular}{|c|c|c|c|c|c|c|}
\hline \multirow[b]{3}{*}{ Attribute Clusters } & \multirow{2}{*}{\multicolumn{2}{|c|}{$\begin{array}{c}\text { Entire Sample } \\
(n=307)\end{array}$}} & \multicolumn{4}{|c|}{ Experience Groups' } \\
\hline & & & \multirow[b]{2}{*}{$\begin{array}{l}\text { Anova } \\
\text { F-Test }\end{array}$} & \multirow[b]{2}{*}{$\begin{array}{c}I \\
(\mathrm{n}=51)\end{array}$} & \multirow[b]{2}{*}{$\underset{(n-48)}{\text { II }}$} & \multirow[b]{2}{*}{$\underset{(n=146)}{\text { III }}$} \\
\hline & Mean & $\begin{array}{l}\text { Standard } \\
\text { Deviation }\end{array}$ & & & & \\
\hline \multicolumn{7}{|l|}{ Selting Altribute } \\
\hline Resource Characteristics (wildlife, wide views, etc.) & 3.1 & 0.8 & $11.08^{*}$ & $3.5 \mathrm{a}^{2}$ & $3.3 \mathrm{a}$ & $2.9 \mathrm{~b}$ \\
\hline Rugged Terrain & 2.9 & 1.1 & $10.17^{*}$ & $3.5 \mathrm{a}$ & $3.0 \mathrm{~b}$ & $2.7 \mathrm{~b}$ \\
\hline Fish & 2.5 & 1.5 & 3.78 & - & - & - \\
\hline Water Without Access & 2.4 & 1.3 & $13.00^{\circ}$ & $.3 .0 \mathrm{a}$ & $2.9 \mathrm{a}$ & $2.1 \mathrm{~b}$ \\
\hline Information & 1.9 & 1.4 & 0.19 & - & - & - \\
\hline Easy Travel & 1.6 & 1.2 & 1.91 & - & - & - \\
\hline Growding-Seeing Others & -1.6 & 1.2 & $14.50^{*}$ & $-1.8 \mathrm{a}$ & $-2.2 \mathrm{a}$ & $-1.2 \mathrm{~b}$ \\
\hline Structures & -1.9 & 1.3 & $6.11^{\bullet}$ & $-2.4 a$ & $-2.1 \mathrm{a}, \mathbf{b}$ & $-1.7 b$ \\
\hline Trail Impacts & -2.0 & 1.3 & -.14 & - & - & - \\
\hline Absence of Regulations & -2.1 & 1.1 & $4.42^{\circ}$ & $-2.5 a$ & $-1.9 b$ & $-2.0 b$ \\
\hline Doge & -2.1 & 1.3 & 0.41 & - & - & - \\
\hline Outfitters & -2.1 & 1.3 & 0.61 & - & - & - \\
\hline Domestic Animals & -2.1 & 1.3 & 4.90 & - & - & - \\
\hline Soil-Vegetation Impacts & -2.2 & 1.0 & 2.86 & - & - & - \\
\hline Crowding-Contacting Others & -2.7 & 1.0 & 3.69 & - & - & - \\
\hline Violations of Wildland Ethics & -2.7 & 0.8 & $16.59^{\circ}$ & $-3.1 \mathrm{a}$ & $-2.9 \mathrm{a}$ & $-2.5 b$ \\
\hline
\end{tabular}


Restrictions on Domestic Livestock

General Information

$\begin{array}{lllll}1.7 & 2.39 & - & - & - \\ 1.4 & 1.09 & \overline{2} & \overline{2} & - \\ 1.5 & 5.04^{\circ} & 2.7 \mathrm{a} & 2.3 \mathrm{a}, \mathrm{b} & 1.9 \mathrm{~b} \\ 1.7 & 5.85^{\circ} & 2.5 \mathrm{a} & 1.9 \mathrm{a}, \mathrm{b} & 1.6 \mathrm{~b} \\ 1.4 & 2.11 & - & - & - \\ 1.7 & 3.45^{\circ} & 1.9 \mathrm{a} & 1.0 \mathrm{~b} & 1.3 \mathrm{a}, \mathrm{b} \\ 1.4 & 2.45 & \overline{1} & - & - \\ 1.7 & 2.29 & - & - & - \\ 2.1 & 0.70 & - & - & - \\ 1.6 & 1.29 & - & - & - \\ 1.6 & 0.47 & - & - & -0 \mathrm{~b} \\ 1.1 & 5.57^{\circ} & -0.4 \mathrm{a} & -0.6 \mathrm{a} & - \\ 1.8 & 1.87 & - & - & - \\ 1.7 & 0.50 & - & - & -\end{array}$

Commercial Groups

Restrictions Based on Size of Group

Resource Restoration

High Enforcement of Regulations

Provision of Information-Reduction of Uncertainty

Fish Stocking

Restrictions on Pets in Backcountry

Special Fishing Regulations

No Restrictions on Camp Ares

Development Related Actions

High Reatriction on Public Use

$-0.4$

'Cluster scores were computed as the mean of valid scores on items within a cluster. See Table 4 for items composing each cluster. The response format for items ranged from Most Strongly Adds ( + 4) through Neither Adda nor Detracts (0) to Most Strongly Detracts $(-4)$ from Satisfaction.

${ }^{3}$ Means with different subscripts are those which differed significantly $(p<, 05)$ using Student-Neuman-Keuls test for differences between means.

- These tests were statistically significant $(\mathrm{p}<.05)$. 
addition, this group has means more positive than Group II on being with similar people, meeting new people and security.

\section{User Group Differences on Activities, Settings and Potential Management Actions}

The percentages of each experience group which had engaged in seven recreation activities during the trip on which they were interviewed is shown in Table 3. A chi-square test showed that activity participation did not differ significantly $(p<.05)$ among the groups for those activities which showed high rates of use (fishing, hiking, photography, and camping) or low rates of use (horseback riding). However, participation in those two activities (mountain climbing and nature study) which had more moderate rates of use was significantly different. It is interesting that Group I which was distinguished by its very high score on the risk-taking cluster had a considerably higher percentage of users who reported they had engaged in mountain climbing and nature study.

Experience groups differed significantly on 7 of the 16 setting-attribute clusters and 4 of the 15 management action clusters (Table 2). Though statistically significant differences were found, the magnitude of the differences is not as great as those found for experience outcomes. The greatest separation, .90 , was found for the setting attribute cluster, water without access, and the management action clusters, restrictions on outfitter and commercial groups and restrictions based on group size.

Group I differed from Group II and III in its higher mean for rugged terrain and lower mean for absence of regulations. Consistent with its low ratings on absence of regulations, Group I had a higher mean for the management action, enforcement of regulations, than did Group II. Group I's high mean for rugged terrain might be expected given its high-risk orientation and greater participation in mountain climbing.

TABLE 3

\section{Number and Percentage of Participants in Wilderness Activities in Each Experience Group}

\begin{tabular}{|c|c|c|c|}
\hline Activity & $\begin{array}{c}I \\
(n-51)\end{array}$ & $\begin{array}{c}\text { Experience Groups } \\
\text { II } \\
(n-48)\end{array}$ & $\begin{array}{c}\text { III } \\
(n \times 146)\end{array}$ \\
\hline $\begin{array}{l}\text { Mountain Climbing }{ }^{1} \\
\text { Fishing } \\
\text { Horseback Riding } \\
\text { Hiking } \\
\text { Nature Study } 1 \\
\text { Photography } \\
\text { Camping }\end{array}$ & $\begin{array}{l}22(43 \%) \\
38(75 \%) \\
0(0 \%) \\
49(96 \%) \\
25(49 \%) \\
45(88 \%) \\
49(96 \%)\end{array}$ & $\begin{array}{c}5(10 \%) \\
33(70 \%) \\
1(2 \%) \\
48(100 \%) \\
14(29 \%) \\
39(81 \%) \\
47(98 \%)\end{array}$ & $\begin{array}{c}36(25 \%) \\
85(58 \%) \\
6(4 \%) \\
139(95 \%) \\
38(26 \%) \\
124(84 \%) \\
134(92 \%)\end{array}$ \\
\hline
\end{tabular}

'These activities showed significant differences $(p<.05)$ between groups using a Chi-square test. 


\section{TABLE 4}

Questionnaire Items Groups on the Basis of I-Clust Variable Cluster Analysis.

\section{Psychological Outcome Clusters}

Relationships with Natue (Alphs' $=0.62$ )

Enjoying the sights and sounds of nature Learning more about nature

Escaping Physical Pressure (Alpha $=0.73$ )

Experiencing the peace and calm

Experiencing tranquility

Experiencing solitude

Getting away from crowded situations for awhile

Being away from crowds of people

Exercise-Physical Fitness (Alpha - 0.81)

Getting exercise

Keeping physically fit

General Learning (Alpha $=0.82$ )

Discovering something new

Exploring the area

Getting to know the lay of the land

Learning about the topography of the land

\section{Escaping Personal and Social Pressure}

(Alpha - 0.51)

Avoiding everyday responsibility for awhile

Releasing or reducing built-up tennion

\section{Autonomy (Alpha - 0.83)}

Do things your own way

Being free to make your own choicea

Being in control of things that happen

Feeling free from society's restrictions

Getting away from the demands of other people.

Getting away from the usual demands of life

Being with Other People (Alpha - 0.53)

Being with members of your group

Being with others who enjoy doing the same things as you

Achievement-Self Realization (Alpha = 0.86)

Learning more about yourself

Thinking about your personal values

Doing something not done by everyone

Challenging nature with your skilla

Feeling your independence
Ápplying your skill,

Developing your skills and abilities

Learning what you are capable of

Developing a sense of self pride

Gaining a sense of accomplishment

Family Togetherness

Doing something with your family

Security (Alpha $=0.58$ )

Being near considerate people

Being near others who could help you if you needed them

Risk Taking (Alpha $=0,67$ )

Taking risks

Chancing dangerous situations

Experiencing the risks involved

Leadership (Alpha = 0.84)

Sharing your outdoor skills with others

Teaching your outdoor skills to others

Sharing your knowledge with others

Helping direct the activities of others

Meeting-Observing New People (Alpha 0.81)

Talking to other people in the area

Meeting other people in the area

\section{Selting Attribule Clusters}

Resource Characteristics (Alpha $=0.73$ )

Elk

Bighom sheep

Petrified wood

Meandering streams

Wide views

A variety of birds

Wildfowers

Rugged Terrain (Alpha $=0.82$ )

Rugged terrain

Barren rocky peaks

Stoep rugged trailg which tax your endurance

Steep terrain

Fish (Alpha = 0.91)

Catchable golden trout

Catchable cutthroat trout

Good fishing lakes

Good fishing streams 
Selting Altribule Clusters - Continued

Water Without Access (Alpha = 0.77)

Lakes with no trails to them

Long stretches of stream with no trails to them

Beaver ponds with no access

Isolated lakes

Information (Alpha = 0.62)

Avalability of information describing recreation use levels

Availability of information describing the natural history of the area

Availability of information describing recreation opportunities in the area

Easy Travel (Alpha $=0.75$ )

Trails with switchbacks which make it easier to climb steep gradea

Directional signs with mileages to destinations

Footbridges over boggy areas

Well-maintained trails free of obstacles

Well-maintained footpaths

Crowding-Seeing Others (Alpha $=0.67$ )

Large organized climbing groups

Large groups (ten and up)

Other recreationists on trail

Seeing others near your campsite

Structures (Alpha - 0.62)

Structures such as lean-tos at campsites

Hitching rails at campaites

Man-made fences

Trail Impacts (Alpha $=0.76$ )

Hikers making shortcuts

Shortcuts which cut across trails with switchbacks

Horseriders making shortcuts

Absence of Regulations (Alpha $=0.69$ )

Enforcement of regulations

Absence of regulations

Regulations requiring people to pack out trash

Unobeyed regulations

Equitable regulations for horacriders

Equitable regulations for outfitters
Dogs (Alpha = 0.72)

Dogu chasing wildlife

Dog droppings on trail

Dogs with other recreationists

Outfitters (Alpha - 0.70)

Outfitter tents left standing while not being used

Horieriders that inconvenience you

Domestic Animals (Alpha $=0.85$ )

Horse droppings on trail

Hikers and horseriders using the same trail

Domestic livestock grazing in the areas you hike through

Domestic livestock grazing in areas you would like to camp

Signa of domeatic livestock having been near your campsite

Soil-Vegetation Impacts (Alpha $\mathbf{- 0 . 7 2 )}$

Worn vegetation around lakea

Deeply eroded trails

Soil erosion around campsites

\section{Crowding-Contacting Others (AJpha -}

0.71)

Campsites too close together

Camping in overcrowded surroundings

Hikers who inconvenience you

Commercial groups who inconverience you

Violations of Wildland Ethics (Alpha -

0.89)

Loud recreationists

Signs of improper disposal of human waste

Unclear water

Litter around campsites

Others using water improperly

Areas stripped of firewood

Tents visible

Evidence of numerous campfiren 


\section{Management Action Clusters}

Restriction on Domestic Livestock (Alpha - 0.83)

Prohibit domestic livestock on highly used trails

Prohibit domestic livestock from grazing near high use camping areas

General Information (Alpha $=0.67$ )

Make information packet on natural history, flora and fauna of area

Make available information on regulations

Restrictions on Outfitters and Commercial

Groups (Alpha = 0.8)

Disallow outfitters in high use areas

Restrict where commercial groups may camp

Disallow commercial groups to use high use areas

Prohibit more than 10 horses per party

Allow horseriders and pack animals at only central campsites

Restrict horseriders and pack animals to certain trails

Restrictions Based on Size of Group

(Alpha = 0.78)

Allow large groups only in certain areas

Create regulations restricting party size to 10 or less

Require permits for large groups

Resource Restoration (Alpha -0.48 )

Fill and harden eroded trails

Revegetate areas made bare by campers

High Enforcement of Regulations (Alpha

$$
\text { - 0.61) }
$$

Increase the number of backcountry rangers for stronger enforcement of regulations

Place heavy fines (over \$50) for violation of wilderness regulations

Provision of Information-Reduction of Uncertainty (Alpha = 0.77)

Make an easily obtainable information packet which describes where good fishing opportunities can be found

Make easily obtainable mapa which show campsites according to how heavily they are used

Make easily obtainable detailed maps on the wilderness

Ensure well-maintained trails free of obstacles

Ensure well-maintained and accurate directional signs

Fish Stocking (Alpha $=0.81$ )

Discontinue fish stocking in high use areas $^{2}$

Discontinue fish stocking in backcountry ${ }^{2}$

Increase fish stocking in the backcountry

Restrictions on Pets in Backcountry (Alpha

- 0.84)

Create regulations stating that pets be kept on a leash in backcountry

Create regulations prohibiting pets in high use areas

Prohibit pets in the backeountry

Special Fishing Regulations (Alpha -

0.54)

Create regulations which restrict some lakes and streams to fly fishing only

Place special ereel limits which limit the number of fish kept in wilderness

No Restrictions on Camp Area (Alpha -

0.74)

Prohibit camping within 100 feet of lakeshores?

Create areas where no overnight camping is permitted ${ }^{2}$

Prohibit campfires in the backcountry ${ }^{2}$

Designate lakes where campfires are allowed ${ }^{2}$

Make no restrictions on where you could camp

Make no restrictions on where campfirea could be made

Restrict the number of designated campsites near heavily used lakes 



'Cronbach's Alpha is an internal consistency measure of reliability.

${ }^{2} \mathrm{~S}$ coring reversed in forming clusters.

With the exception of differences on rugged terrain and regulations, Group II had quite similar setting preference and management preference means to Group I. However, Group III was, found to have several differences with one or both of the other Groups. The setting attributes, resource characteristics and water without access, were found to add less to the satisfaction of Group III and crowding (seeing others) and violations of wildland ethics detracted less from their satisfaction than they did for both other groups. Further, Group III did not rate man-made structures as negatively as did Group I and for the management actions dealing with structures, Group III had a neutral mean $(0)$ while the other two groups had negative means. In addition, Group III rated group size restrictions and restrictions on outfitters and commercial groups lower than did Group I. From these differences we conclude that Group III places less importance on a highly natural environment than do the other groups.

\section{Discussion}

Data from this study have implications of both an applied and conceptual nature. Given that the conceptual implications raise practical questions, they preface an explanation of how these data may be used in experience based setting management. 


\section{Concept Development}

This study hypothesized that wilderness recreationists could be segmented into experience groups and that the groups would differ on the activities and attributes of the settings they prefer. Results of the study indicate we can accept each hypothesis. The confirmation of these hypotheses drawn from the Driver and Brown model of recreation choice gives support to the model. Our supposition was that if, as the model proposes, recreationists choose settings and activities on the basis of how they are expected to meet valued experience outcomes, then we would anticipate that users with different experience preferences would have different setting and activity preferences. It is emphasized that only limited support is provided for the model. In this study only a limited set of conclusions drawn from the model were tested. No tests were made of directionality or causality among the model components nor of the nature of relationships between specific activities, attributes and experiences. These are all areas that need research.

Also, while accepting the hypotheses of this study we give caution regarding an important issue in the use of psychometric survey instruments. This issue asks whether or not responses on rating scales, such as those asking for evaluation of an attribute's effect on satisfaction, actually give an indication of how recreationists will behave in choosing locations to recreate and in reacting to management (Heberlein 1973). Further specification of this question asks how many attribute or experience preference differences should be found and what should the magnitude of those differences be before differences in observable behavior can be expected?

In this study we did not find large mean differences between groups on their ratings of settings and management attributes. Yet, recognizing the limitations in questionnaire construction and interpretation, and other forms of potential bias, statistically significant differences should be predictive of behavioral choices of recreation settings and activities made by recreationists. We have taken this position in part because the study population is a relatively homogeneous group, wilderness recreationists, and large mean differences among them simply should not be expected. With this group, small differences in their preference structure may result in differences in the locations they recreate within a wilderness, which themselves are not likely to be tremendously different.

However, we also take the position that the validity of this approach needs to be established. Questions of construct validity (are we measuring the concepts we are intending?), predictive validity (can we actually predict an individual's choice of environment from information specified in this model?) and content validity (have we measured all the salient and discriminating attributes for a group of recreationists?) must be addressed in future research.

\section{Applications of Data}

Recognizing these limitations we might still make recommendations about how the study data can be useful in experience based setting manage- 
ment. To help facilitate discussion of the practical applications of the study findings, the three experience groups will be given names which reflect the most discriminating experience preferences of those groups. Group I was distinguished particularly by its higher ratings on the risk-taking and achievement-self realization clusters, so it will be called the High Risk/Achievement Group. Because Group II scored considerably lower on the security, risktaking, and meeting and observing new people clusters, it will be called the Low Risk/Sacial Interaction Group. Group III will be called the Norm because it represented the largest proportion of the users and overall tended to show the least difference from the other segments.

These group labels reflect the implications that group differences have for management. Experiential satisfaction for the Norm group appears to be less dependent on physical and social surroundings than it does for the other groups. Physical and social wilderness setting attribute standards may be less restrictive for this group than for the other two groups.

The preferences of the Low Risk/Social Interaction group are likely to be met at locations where there is a low probability of seeing other people and encountering dangerous situations. This group's lower scores on the crowding and rugged terrain setting attribute clusters and low proportion of mountain climbers help support this position. Additionally, this group responded more favorably than the others to restrictions on group size.

Rough, rugged areas seem most likely to meet the experience and activity preferences of the High Risk/Achievement Group. They had the highest proportion of members engaged in mountain climbing and nature study (Table 3) the latter of which corresponds to their slightly higher score on the relationships with nature and general learning experience outcome clusters. They also scored the rugged terrain setting attribute cluster the highest, corresponding to their most distinguishing experience preferences. No differences directly related to their distinguishing preference were found on the management action clusters (Table 2), though they do appear to be slightly more receptive than other groups to regulations and enforcement.

As has been suggested in related studies (e.g., Brown and Haas 1980; Haas et al. 1980) these experiential data can, with additional judgment, aid managers at several points in the planning process. For example, by focusing on the setting attributes valued differentially for these experiences, managers might develop criteria and standards for inventorying land for its ability to provide different recreation opportunities. The criteria would be formulated in terms of physical features (e.g., type of terrain), social characteristics (e.g., number of encounters) and managerial actions (e.g., restrictions on outfitters). Of the areas included in this study, the locations easily accessible to people, domestic animals, outfitters, or commercial groups are more acceptable to the Norm Group than to the other groups. Areas of moderate accessibility, litthe or no development, low probability of encounters, and natural surroundings are more acceptable to the Low Risk/Social Interaction Group. Areas with rough or undeveloped access, rugged terrain at destination sites, high naturalness, and low probability of encounter appeal to the High Risk/ Achievement Group. When a decision is made that a given area is to provide a 
specific type of experience opportunity, management actions can be selected which facilitate the type of experience desired. For instance, to help users have low risk/social interaction experiences, managers might establish relatively inaccessible zones where fewer small groups might travel. This would increase the probability of users realizing a higher degree of isolation. Management actions to accommodate higher numbers of the Norm Group might emphasize providing outhouses and hardening campsites. For the High Risk/Achievement Group, a do-nothing alternative might be preferable. Leaving isolated and remote areas untrailed may provide opportunities for their desired experiences.

\section{Conclessions}

The general intent of this study was to provide a test of concepts inherent in experience based setting management for outdoor recreation areas. Study results offer some support for these concepts. Recognizing the limitations of the study we have offered an illustration of how its results might aid in implementing experience based setting management. The study points out, however, that there is a need for further research which will aid in validating and refining these concepts.

\section{Deferences}

Ballman G.E., Knopp, T.B., and Merriam, L.C., Sr. 1981. Managing the environment for diverse recieation; cross country skiing in Minnesota. Agr. Exp. Stn. Bull. S44, Forestry Seriea 39, St. Paul, Minn.

Brown, P.J. 1981. Paychological benefits of outdoor recreation. p. 13-17 in social benefits of oatdoor necreation, J. R. Kelly (ed.). Leisure Behavior Reacarch Lob. Univ. of III., Champaigm, III.

Brown, P.J., Driver, B.L., and MeConnell, C. 1978. The opportunity spectrum concept and behavioral information in outdoor recreation resource supply inventoriea: background and

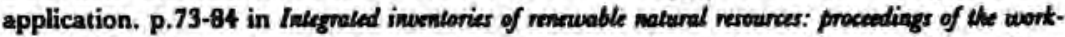
shop. USDA Forest Service Gen. Tech. Rep. RM-55, Rocky Mtn. For. and Range Exp. Sta., Fort Collins, Colo.

Brown, P.J., Dyer, A.A., and Whaley, R.S. 1973. Recreation research-so what? Journal of Leisure Research 5(1):16-24.

Brown, P.J. and Haus, G.E. 1980. Wildemess rocreation experience; the Rawah case. Journal of Leinure Research 12(3):229-241.

Brown, P.J. and Ross, D.H, 1982. Recreation experience preferences as variables in recreation setting preference decisions. In preas: Proceedings of the 1981 NRPA symposium forest and rivers session. Agr. Exp. Stn., Univ. of Minn.

Buist, L.J. and Hoots, T.A. 1982. Recreation opportunity spectrum approach to resource planning. Joumal of Forestry 30(2):84-86.

Clark, R.N. and Stankey, G.H. 1979. The recreation opportunity spectrum: a framework for planning management and research. USDA Gen. Tech. Rep. PNW-98. Pac. Northwest For. and Range Exp. Stn., Seattle, Wash.

Cronbach, L.J. 1951. Coefficient alpha and the internal structure of tests. Prychometrika (16)297-334.

Driver, B.L. 1976. Quantification of outdoor recreationsts' preferences. p. 165-187 in Reseurch camping and environmenlal education. Betty van der Smissen (ed.) Penn State Series II, Univ. Park, Pa. 
Driver, B.L., and Brown, P.J 1975. A socio-psychological definition of recreation demand, with implications for recreation resource planning. p. 64-88 in Assessing demand for ouldoor recreation. National Academy of Sciences, Wash., D.C.

Driver, B.L. and Brown, P.J. 1978. The opportunity spectrum concept and behavioral information in outdoor recreation resource supply inventories: a rationale. p. 24-31 in Integrated inventories of renewable natural resources: proceedings of the wortshop, USDA Forest Service Gen. Tech. Rep. RM-55. Rocky Mtn. For. and Range Exp. Stn., Fort Collins, Colo.

Driver, B.L. and Cooksey, R.W. 1978. Preferred psychological outcomes of recreational fishing. p.27-40 in Catch and release fishing as a management tool: a national sport fishing symposium. R.A. Barnhart and T.D. Roelofs (ed.). Humboldt State University, Arcata, Calif.

Driver, B.L. and Rosenthal, D.H. 1982. Measuring and improving the effectiveness of public outdoor recreation programs. Report on a recreation output resources workshop Dec. 11-14, 1979, Harpers Ferry, W.V. Dept. of Human Kinetics and Leisure Studies, George Washington Univ, , Wash., D.C.

Driver, B.L., and Tocher, S.R. 1970. Toward a behavioral interpretation of recreation engagements, with implications for planning. p. 9-31 in Elements of outdoor recreation planning. B.L. Driver, (ed.). Univ. Microfilms Mich., Ann Artor, Mich.

Haas, G.E., Driver, B.L. and Brown, P.J. 1980. A study of ski touring experiences on the White River National Forest. p. 25-30 in Proceedings of the North American symposium on dispersed winter recreation. Office of Special Programs Educational Series 2-3, Agr. Ext. Ser., Univ. of.Minn., St. Paul, Minn.

Haas, G.E., Driver, B.L., Brown, P.J. 1981. Measuring wilderness recreation experiences. p.25-30 in Proceedings of the wilderness psychology group annual conference. L. Cannon (ed.). Dept. of Psychology, Univ, of N.H., Durham, N.H.

Harris, C.C. 1981. Experiential outcomes as social benefits of outdoor recreation. p. 18-25 in Social benefits of outdoor recreation, J.R. Kelly (ed.). Leisure Behavior Research Lab, Univ. of Ill., Champaign, Ill.

Hautaluoma, J. and Brown, P.J. 1978. Attributes of the deer hunting experience: a cluster analytic study. Joumal of Leisure Research 10(4):271-287.

Heberlein, T.A. 1973. Social psychological assumptions of user attitude surveys: the case of the wildernism scale. Joumal of Leisure Research 5(3):18-33.

Hendee, J.C. 1974. A multiple-satisfaction approach to game management. Wildlife Society Bulletin 2(3):104-113.

Lawler, E.E. 1973. Motivation in work organizations. Monterey, Calif.: Brooks/Cole.

Lucas, R.C., and Stankey, G.H. 1974. Social carrying capacity for backcountry recreation. p. 14-23 in Outdoor recreation research: applying the results. USDA Forest Service Gen. Tech. Rep. NC-9, North Cent. For. Exp. Stn., St. Paul, Minn.

Manfredo, M.J., Brown, P.J., and Haas, G.E. 1980. Fishermen values in wilderness. Proceedings of the Western Association of Fish and Wildlife Agencies. 52:276-297.

McLaughlin, W.J. and Paradice, W.E.J. 1980. Using visitor preference information to guide dispersed winter recreation management for cross country skiing and snowmobiling. p. 64-72 in Proceedings of the North American symposium on dispersed winter recreation. Office of Special Programs Educational Series 2-3. Agr. Ext. Ser., Univ. of Minn., St. Paul, Minn.

Revelle, W. 1977. Hierarchical cluster analysis-computer program: Northwestern Univ., Evanston, III.

Stankey, G.H. 1974. Criteria for the determination of recreational carrying capacity in the Colorado River Basin. In Environmental management in the Colorado river basin. A.B. Crawford and D,F. Peterson (eds.). Utah State Univ. Press, Logan, Utah.

Wagar, J.A. 1964. The carrying capacity of wildlands for recreation. Forest Science Monograph 7. 
Wagar, J.A. 1974. Recreational carrying capacity reconsidered. Journal of Forestry 72(5):274-278.

Wolfe, J.H. 1978. Comparative cluster analysis of patterns of vocational interest, Multivariale Behavioral Research 13(January):33-44.

Wolfe, J.H. 1970. Pattern clustering by multivariate mixture analyses. Multivariale Behavioral Research 5(July)329-350. 